\title{
SIMULATION OF A POWER SYSTEM CONSIDERING ACTIVE POWER LOSSES AND SEASONS
}

\author{
Lucian-Ioan DULĂU ${ }^{1}$, Dorin BIC $\breve{A}^{2}$ \\ ${ }^{1,2}$ University of Medicine, Pharmacy, Science and Technology „, George Emil Palade” of Târgu Mureș \\ Gh. Marinescu 38, Târgu Mureș, Romania \\ ${ }^{1}$ lucian.dulau@umfst.ro \\ ${ }^{2}$ dorin.bica@umfst.ro
}

\begin{abstract}
In this paper is presented the simulation of a power system. The simulations performed are considering the seasons (spring, summer, autumn and winter). The system has 39 buses, 46 power lines, 13 generating units, 19 loads and 2 storage units. Of the 13 generating units, 3 are distributed generation sources based on renewable energy. There are also 2 battery storage units. The simulation considers the active power supplied by the generating and storage units, respectively the active power losses. The results give the power supplied by each generating unit for each season.
\end{abstract}

Key words: simulation, seasons, generation cost, active power losses, order of power dispatch, priority dispatch

\section{Introduction}

The simulation of power systems with an increasing number of distributed generation sources and storage units is important.

Distributed generation is a term that refers to the sources that rely on renewable energy, such as solar, wind or hydro, with a power usually lower than 50 MW, installed near or at the load premises. Due to availability of the primary energy source of the renewable energy sources, the power that can be supplied has variations. Therefore, storage units help get a stable and reliable output from these sources.

The main recent research on the simulation of power systems with distributed generators and / or electricity storage units focuses on the implementation of artificial intelligence techniques $[1,2]$, namely the operation, optimization and dispatching of the component systems of the analyzed systems according to different conditions.

The dispatching in [3] was performed considering the power flexibility margin. In [4] it was studied to improve the automatic dispatching so as to be optimal in a system with diverse energy resources.
In [5] was performed a simulation for a system for a short-term (minutes, hour or a day). In [6] was performed a simulation for a grid-connected photovoltaic and battery system.

In [7] was analyzed the management of power flows for a microgrid considering the sources, the state of charge of batteries, the energy level of ultracapacitors, the available power from the PV and the demand of power from the grid operator.

In [8] was performed a digital simulation of an advanced micro-hydro power plant for distributed generation. In [9] the simulation was performed for a microgrid, respectively in [10] for a campus.

The simulation in this paper will be performed considering the seasons (spring, summer, autumn, winter), the power supplied by the distributed generation sources and storage units for these seasons and the power demand for the considered seasons.

The paper is structured as follows. In Section II will be presented the simulation steps, and the system on which the simulations will be performed, in Section III the simulation results and in Section IV the conclusions.

(C) 2021 Published by University Press. This is an open access article under the CC BY-NC-ND license (http://creativecommons.org/licenses/CC-BY-4.0/) 


\section{Simulation steps and system data}

The simulation steps are as follows.

First, the simulation is started.

Second, the season, respectively hour of the simulation is selected.

Third, the generating units are activated so the following conditions are respected:

Power supplied $[M W]-$ Power losses $[M W]=$ Power demand $[M W]$

$$
P_{\text {gmin }} \leq P_{g i} \leq P_{\text {gmax }}
$$

$\mathrm{P}_{\mathrm{gi}}$ is the power that is supplied by a generating unit, in $\mathrm{MW}, \mathrm{P}_{\text {gmin }}$ ang $\mathrm{P}_{\text {gmax }}$ are minimum and maximum power that can be supplied by a generating unit, in MW.

The distributed generation units and storage units are checked if they are connected.

If the distributed generation units and storage units are connected (on-grid), then they will be coupled to the simulation first, having priority, then the rest of the generating units are coupled to the simulation.

If the distributed generation units and storage units are not connected (off-grid), the generating units will be coupled in the simulation in ascending order of their generation cost, first the generating unit with the lowest cost, then the following and so on.

The generation cost (GC) for a generating unit is determined with the following equation:

$$
G C=a \cdot P_{g i}^{2}+b \cdot P_{g i}+c[\text { m.u./ hour }]
$$

$\mathrm{a}$ is the cost of installing a MW for a generating unit in m.u. $/ \mathrm{MWh}^{2}, \mathrm{~b}$ is the cost of the power supplied by a generating unit in m.u./MWh, and c is cost of repair of a generating unit in m.u./h, where m.u. is monetary units.

Fourth, the simulation stops when the condition from equation (1) is respected.

The simulation is performed using the software CitectSCADA [11] for the year's seasons, namely spring, summer, autumn and winter. Each of these seasons have a different power demand, respectively the power that can be supplied by the distributed generating units and battery storage units is also different. The system used for the simulation is presented further, in figure 1.

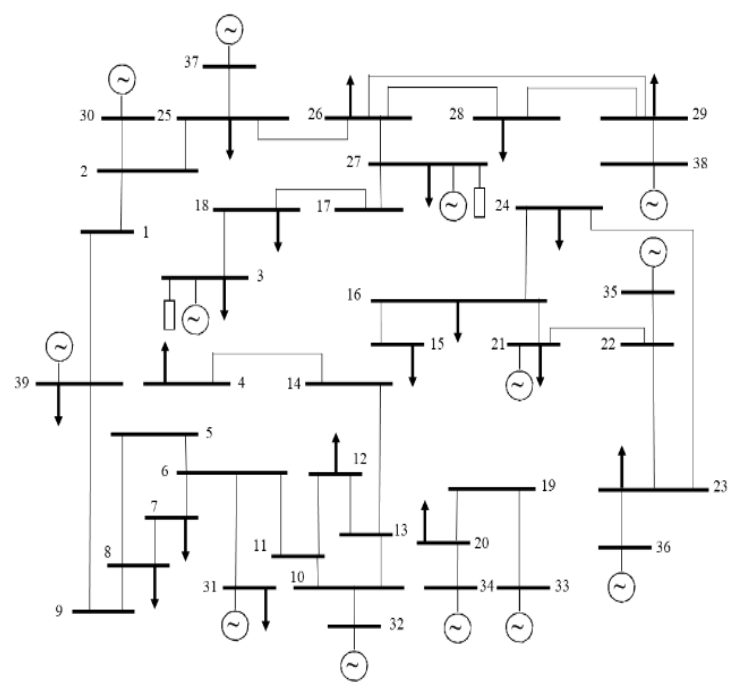

Fig. 1: Test system with 39 buses

The system has 13 generating units, of which 3 are distributed generating units and 2 battery storage units ( 2 photovoltaic power plants at bus 3 , respectively bus 27, and a small-hydro at bus 21). There are also 2 battery storage units at bus 3 , respectively bus 27 . The system has 46 power lines and 19 loads. In table 1 are presented the generating unit data, respectively the cost coefficients for these units in table 2. In table 3 are presented the loads data.

Table 1: Generating unit data

\begin{tabular}{|l|l|l|}
\hline $\begin{array}{l}\text { Generating unit } \\
\text { connected at } \\
\text { bus }\end{array}$ & $\begin{array}{l}\mathrm{P}_{\text {gmin }} \\
{[\mathrm{MW}]}\end{array}$ & $\begin{array}{l}\mathrm{P}_{\text {gmax }} \\
{[\mathrm{MW}]}\end{array}$ \\
\hline 3 & 0 & 5 \\
\hline 21 & 0 & 8 \\
\hline 27 & 0 & 4 \\
\hline 30 & 0 & 80 \\
\hline 31 & 0 & 100 \\
\hline 32 & 0 & 65 \\
\hline 33 & 0 & 63.2 \\
\hline 34 & 0 & 50.8 \\
\hline 35 & 0 & 65 \\
\hline 36 & 0 & 56 \\
\hline 37 & 0 & 54 \\
\hline 38 & 0 & 83 \\
\hline 39 & 0 & 100 \\
\hline
\end{tabular}

Table 2: Generating unit cost coefficients

\begin{tabular}{|l|l|l|l|}
\hline $\begin{array}{l}\text { Generat } \\
\text {-ing unit } \\
\text { at bus }\end{array}$ & $\begin{array}{l}\text { a } \\
{[\text { m.u./MWh }}\end{array}$ & $\begin{array}{l}\text { b } \\
{[\text { m.u./MWh }}\end{array}$ & $\begin{array}{l}\text { c } \\
{[\text { m.u./h }} \\
]\end{array}$ \\
\hline 3 & 0.03 & 6 & 0.005 \\
\hline 21 & 0.14 & 3.75 & 0.009 \\
\hline 27 & 0.025 & 5 & 0.005 \\
\hline 30 & 0.075 & 2.2 & 0.01 \\
\hline 31 & 0.083 & 2.3 & 0.01 \\
\hline 32 & 0.082 & 2.7 & 0.01 \\
\hline 33 & 0.09 & 3.4 & 0.01 \\
\hline 34 & 0.02 & 1.85 & 0.01 \\
\hline
\end{tabular}




\begin{tabular}{|l|l|l|l|}
\hline 35 & 0.12 & 3.6 & 0.01 \\
\hline 36 & 0.085 & 2.9 & 0.01 \\
\hline 37 & 0.095 & 3.45 & 0.01 \\
\hline 38 & 0.09 & 3.25 & 0.01 \\
\hline 39 & 0.077 & 2.8 & 0.01 \\
\hline
\end{tabular}

Table 3: Load data

\begin{tabular}{|l|l|}
\hline $\begin{array}{l}\text { Load connected at } \\
\text { bus }\end{array}$ & $\mathrm{P}[\mathrm{MW}]$ \\
\hline 3 & 32.2 \\
\hline 4 & 30 \\
\hline 7 & 23.38 \\
\hline 8 & 52.2 \\
\hline 12 & 17.5 \\
\hline 15 & 32 \\
\hline 16 & 32.9 \\
\hline 18 & 45.8 \\
\hline 20 & 62.8 \\
\hline 21 & 27.4 \\
\hline 23 & 24.75 \\
\hline 24 & 30.86 \\
\hline 25 & 32.4 \\
\hline 26 & 13.9 \\
\hline 27 & 28.1 \\
\hline 28 & 30.6 \\
\hline 29 & 28.35 \\
\hline 31 & 29.2 \\
\hline 39 & 31.04 \\
\hline
\end{tabular}

The power demand for all the loads for the seasons is presented in figure 2 .

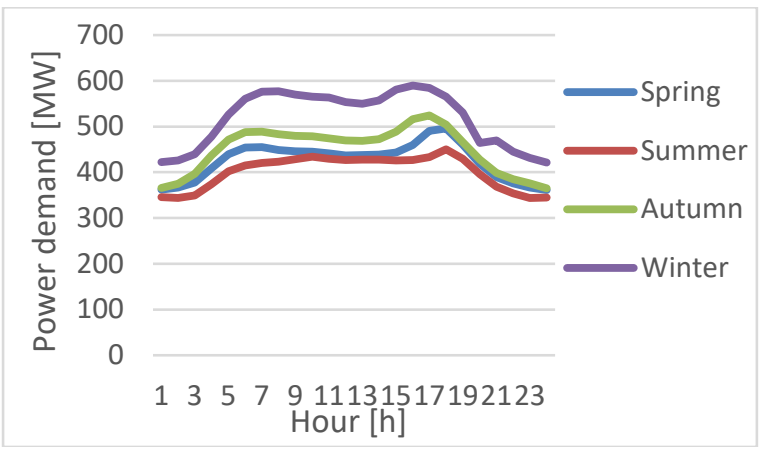

Fig. 2: Power demand for the seasons

The power supplied by the distributed generating units (DGS) and battery storage units (BS) for the seasons is presented in: figure 3 (spring), figure 4 (summer), figure 5 (autumn) and figure 6 (winter).

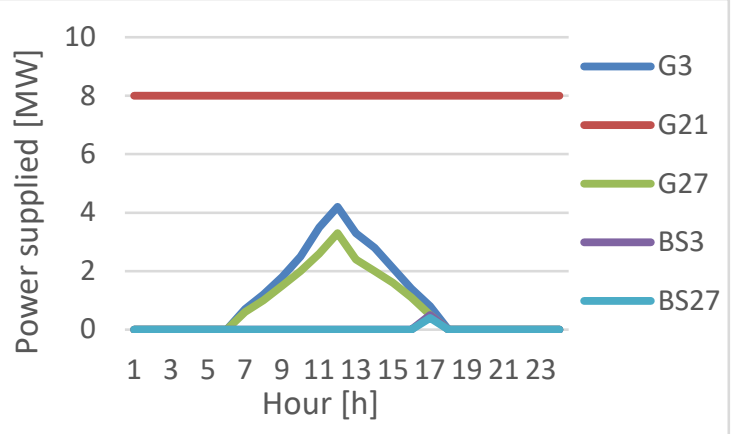

Fig. 3: Power supplied (spring) by DGs and BS

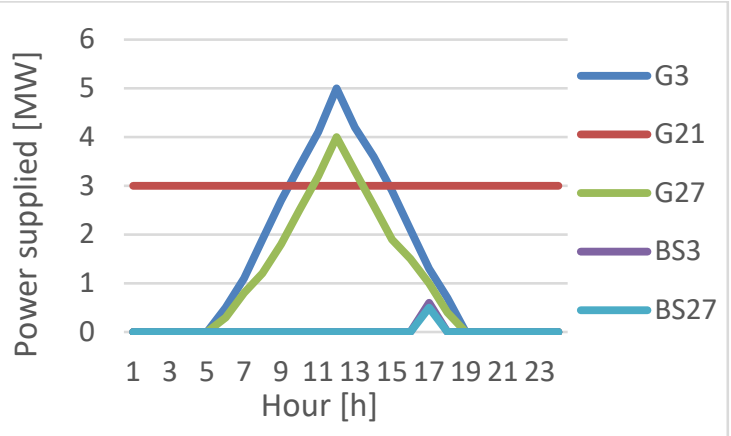

Fig. 4: Power supplied (summer) by DGs and BS

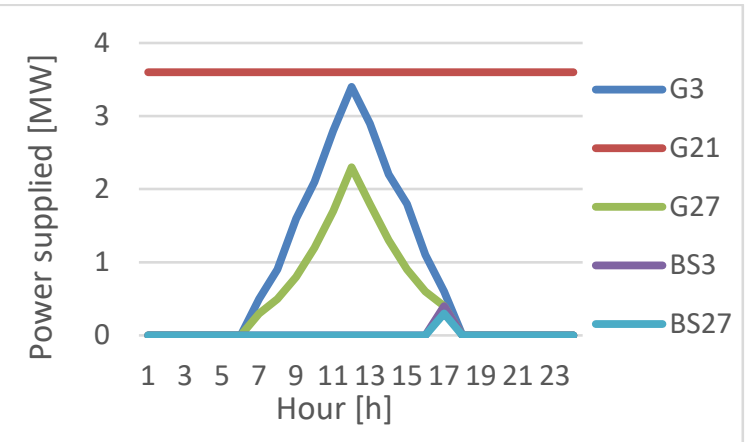

Fig. 5: Power supplied (autumn) by DGs and BS

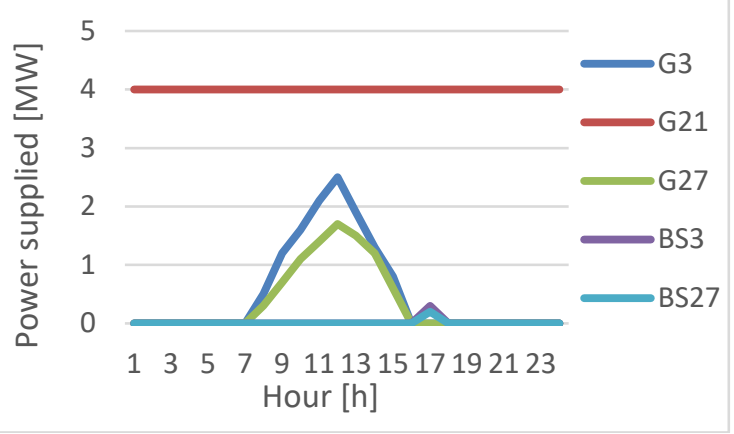

Fig. 6: Power supplied (winter) by DGs and BS

The active power losses for the seasons are presented further in figure 7 (spring), figure 8 (summer), figure 9 (autumn) and figure 10 (winter).

These losses were determined with the NEPLAN software, considering the optimal power flow analyses.

These losses will be considered in the season simulation. 


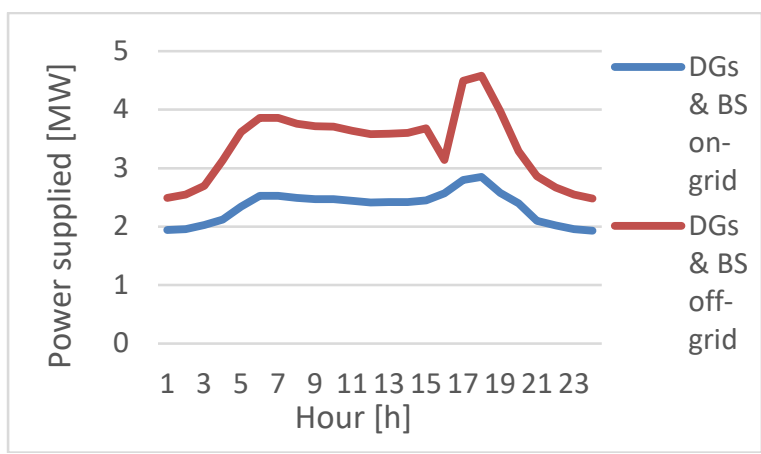

Fig. 7: Power losses (spring)

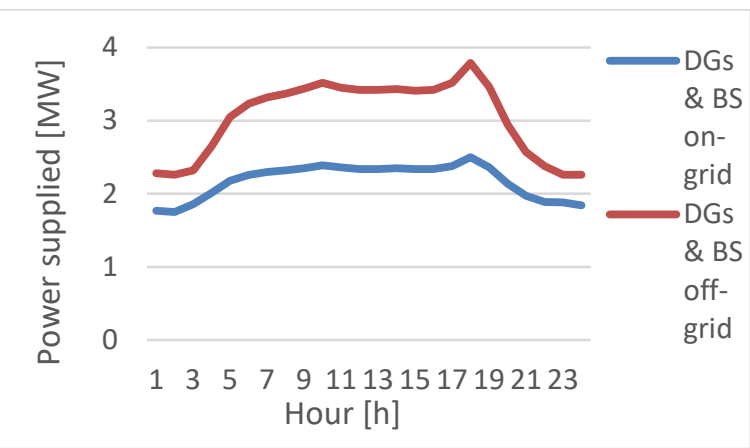

Fig. 8: Power losses (summer)

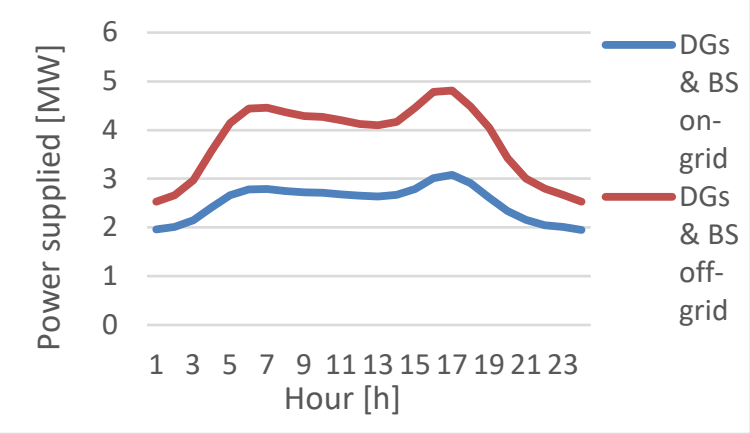

Fig. 9: Power losses (autumn)

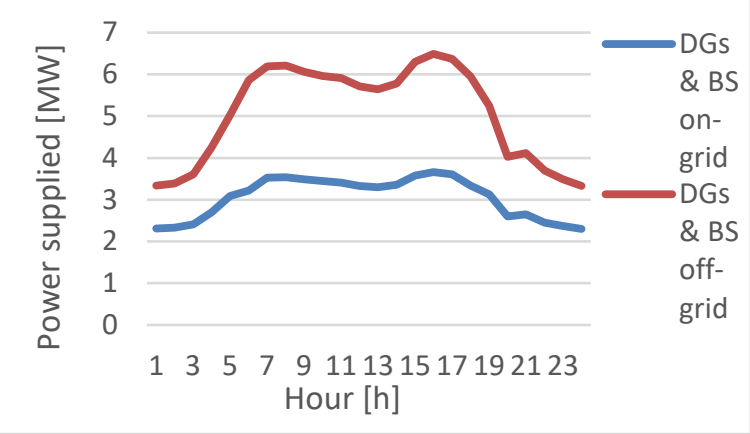

Fig. 10: Power losses (winter)

The interface for the simulation was created with the software CitectSCADA [11] and is presented in figure 11 .

The interface was developed and configured by the authors of the paper considering the information presented above.

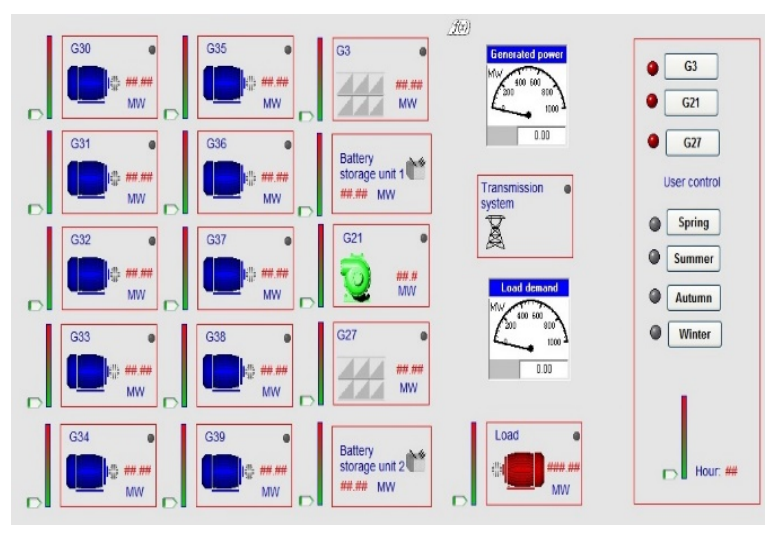

Fig. 11: System simulation interface

The simulation interface contains the following:

- graphic symbols for generators, transmission system, load and power meters that indicate what element they represent;

- numerical objects that indicate the amount of power generated or power demand;

- slide bars that indicate the amount of power generated or power demand considering the use of the generators and load, respectively indicate the hour of the simulation;

- meters that indicate the generated power and power demand at the hour of the simulation;

- buttons that are used to activate or deactivate the distributed generation units and storage units, respectively select a season;

- symbols (lights) that indicate if the generators, load, transmission system, season are activated;

- user control that is used to select the simulation season, activate or deactivate the distributed generation units and storage units, respectively select the hour of the simulation;

- CitectObject $f(x)$ in which we wrote the simulation code considering the information from Section 2.

The most important in the simulation interface are the user control and the CicodeObject.

\section{Simulation results for the seasons}

The simulation results for the considered seasons are presented in: figure 12 and figure 13 for spring, figure 14 and figure 15 for summer, figure 16 and figure 17 for autumn, respectively in figure 18 and figure 19 for winter.

These results consider the two cases: the DGs and $\mathrm{BS}$ are connected, respectively the DGs and BS are not connected.

Therefore, the power dispatch order is presented in table 4 (the DGs and BS are not connected) and table 5 (the DGs and BS are connected). The generation cost $\mathrm{GC}$ is obtained by considering in equation (3) $\mathrm{P}_{\mathrm{gi}}$ is 1 MW. 
Table 4: Season's power dispatch order for DGs and BS not connected

\begin{tabular}{|l|l|l|}
\hline $\begin{array}{l}\text { Generating unit } \\
\text { at bus }\end{array}$ & GC $[\mathrm{m} . \mathrm{u} . / \mathrm{h}]$ & $\begin{array}{l}\text { Power } \\
\text { dispatch } \\
\text { order }\end{array}$ \\
\hline 34 & 1.88 & 1 \\
\hline 30 & 2.285 & 2 \\
\hline 31 & 2.393 & 3 \\
\hline 32 & 2.792 & 4 \\
\hline 39 & 2.887 & 5 \\
\hline 36 & 2.995 & 6 \\
\hline 38 & 3.35 & 7 \\
\hline 33 & 3.5 & 8 \\
\hline 37 & 3.555 & 9 \\
\hline 35 & 3.73 & 10 \\
\hline
\end{tabular}

Table 5: Season's power dispatch order for DGs and BS connected

\begin{tabular}{|l|l|l|}
\hline $\begin{array}{l}\text { Generating and } \\
\text { storage unit at } \\
\text { bus }\end{array}$ & GC [m.u./h] & $\begin{array}{l}\text { Power } \\
\text { dispatch } \\
\text { order }\end{array}$ \\
\hline 21 & 3.899 & 1 \\
\hline 27 & 5.03 & 2 \\
\hline 3 & 6.035 & 3 \\
\hline 34 & 1.88 & 4 \\
\hline 30 & 2.285 & 5 \\
\hline 31 & 2.393 & 6 \\
\hline 32 & 2.792 & 7 \\
\hline 39 & 2.887 & 8 \\
\hline 36 & 2.995 & 9 \\
\hline 38 & 3.35 & 10 \\
\hline 33 & 3.5 & 11 \\
\hline 37 & 3.555 & 12 \\
\hline 35 & 3.73 & 13 \\
\hline
\end{tabular}

The simulation results for all the seasons emphasis that the generating units respected the order. Also, the conditions for the simulations were respected.

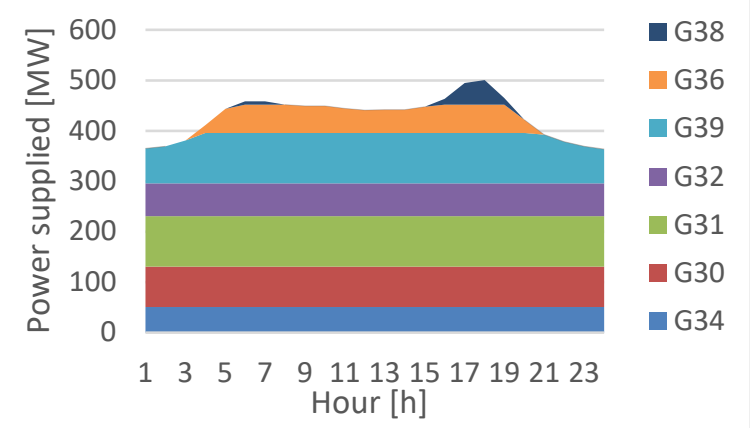

Fig. 12: Simulation results (spring) for DGs and BS not connected

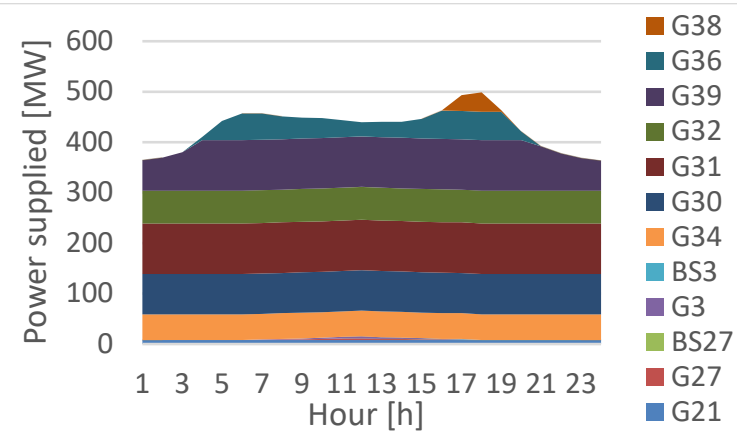

Fig. 13: Simulation results (spring) for DGs and BS connected

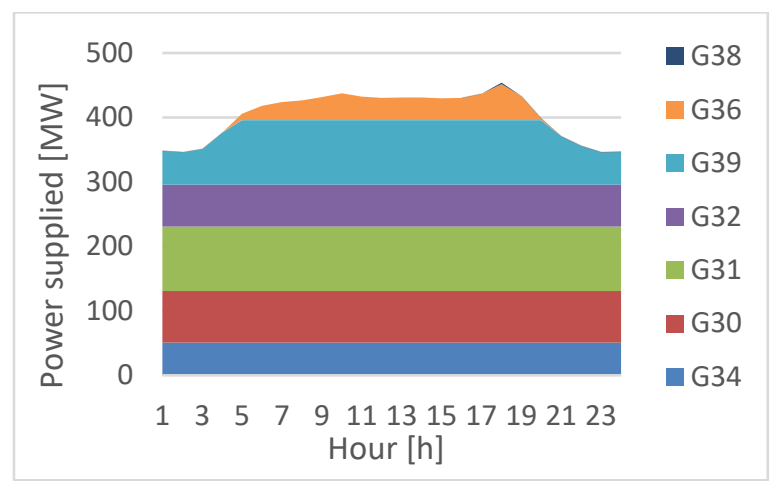

Fig. 14: Simulation results (summer) for DGs and BS not connected

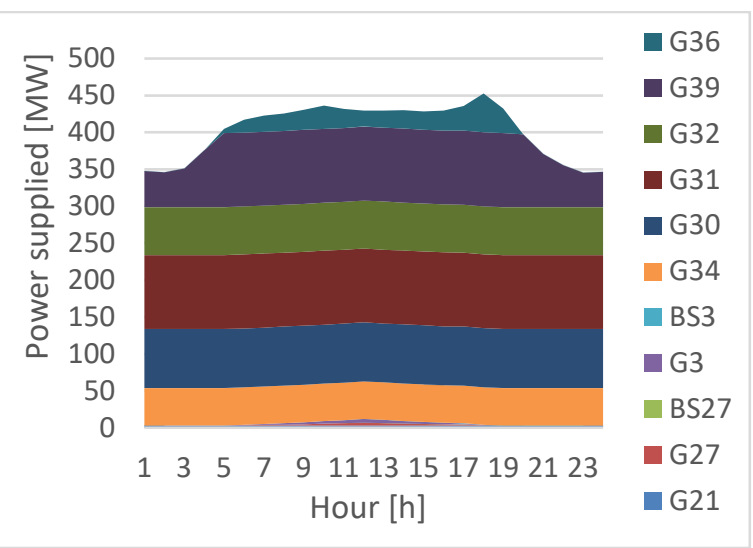

Fig. 15: Simulation results (summer) for DGs and BS connected

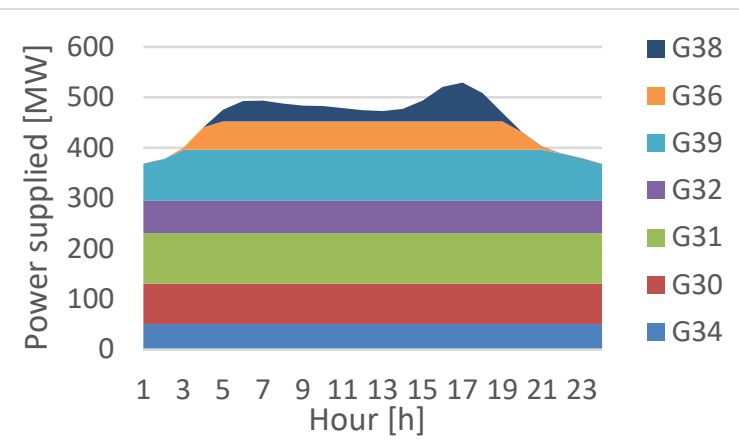

Fig. 16: Simulation results (autumn) for DGs and BS not connected 


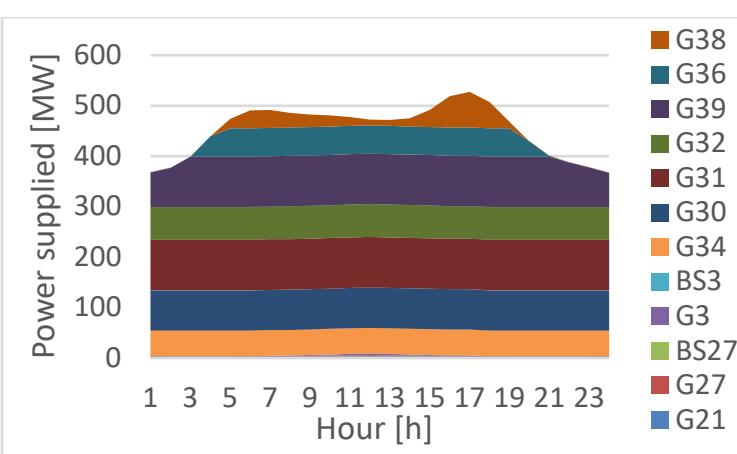

Fig. 17: Simulation results (autumn) for DGs and BS connected

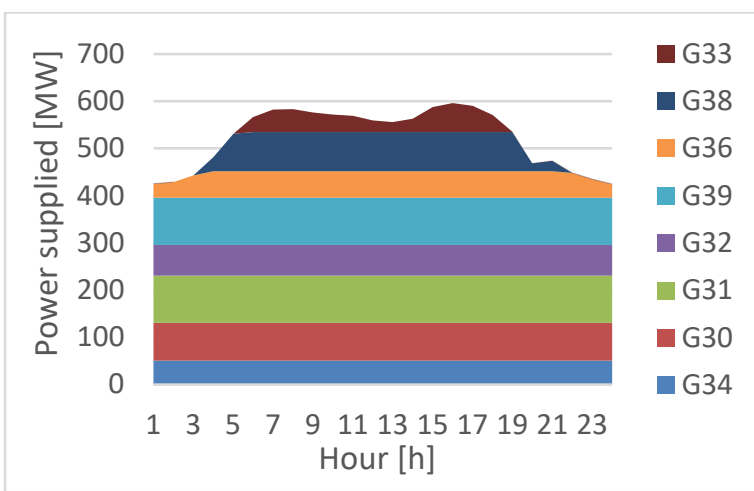

Fig. 18: Simulation results (winter) for DGs and BS not connected

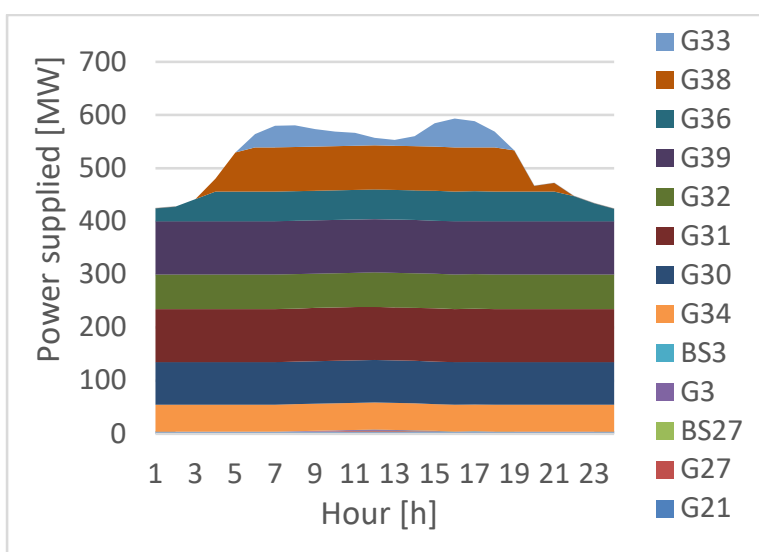

Fig. 19: Simulation results (winter) for DGs and BS connected

Considering the seasons, the number of units that had to be used and the power supplied by them was different. This was caused by the power demand, which was different: in the summer was lower, while in the winter was higher. Therefore, during the simulation the generating units had to adapt their supplied power according to the demand. In all seasons, the following generating units supplied their maximum power: G34, G30, G31 and G32. The generating units G39, G36 and G38 had to supply a certain amount of power to cover the power demand, according to the time of the simulation.

There are also a few particular cases. In the summer G38 had to be used only at 18 o'clock, when the DGs and BS were not connected, in order to cover the power demand. In the winter G33 had to be used in order to cover the power demand.

Also, G37 and G35 were not coupled in the simulations because the power supplied by other generating units was enough to cover the power demand and power losses.

\section{Conclusions}

The performed simulations considered the seasons (spring, summer, autumn, winter), the power supplied by the distributed generation and storage units for the respective seasons and the power demand for the considered seasons.

The simulation performed emphasis that the power demand and power losses were covered by the power supplied for all seasons. In the simulations for all seasons and all hours of the simulation, there were 4 generating units, G34, G30, G31 and G32, that supplied their entire power. The other generating units (G36, G39, G38 and G33) supplied a sufficient amount of power so the load power demand was satisfied.

During the simulations, it was observed that G37, respectively G35 were not coupled in the simulation. This was caused by the other generating units that supplied enough power, so the power demand and power losses were covered.

\section{Acknowledgement}

This work was supported by the University of Medicine, Pharmacy, Science and Technology „George Emil Palade” of Târgu Mureș Research Grant number 10128/2/17.12.2020.

\section{References}

[1] Reyes, L.M. and Baeza, J.M. (2018), Simultaneous Optimization of Topology, Distributed Generation and Energy Storage Systems in Distribution Networks Using the MOHBB-BC Algorithm, 2018 IEEE International Conference on Automation/XXIII Congress of the Chilean Association of Automatic Control (ICA-ACCA), pp. 1-16.

[2] Ospina, J., Gupta, N., Newaz, A., Harper, M., Faruque, M.O., Collins, E.G., Meeker, R. and Lofman, G. (2019), Sampling-Based Model Predictive Control of PV-Integrated Energy Storage System Considering Power Generation Forecast and Real-Time Price, IEEE Power and Energy Technology Systems Journal, Vol. 6, No. 4, pp. 195-207.

[3] Xiao, B., Xiao, Z., Yan, G., Jiang, Z., Dong, L., Wang, M. and Yang, H. (2019), Complementary Coordinated Dispatch of Multi-energy Systems Considering Power Flexibility Margin, 2019 IEEE Innovative Smart Grid Technologies - Asia (ISGT Asia), pp. 3759-3764.

[4] Patel, R., Li, C., Meegahapola, L., McGrath, B. and Yu, X. (2019), Enhancing Optimal 
Automatic Generation Control in a Multi-Area Power System with Diverse Energy Resources, IEEE Transactions on Power Systems, Vol. 34, No. 5, pp. 3465-3475.

[5] Silva, M., Morais, H. and Vale, Z. (2012), An integrated approach for distributed energy resource short-term scheduling in smart grids considering realistic power system simulation, Energy Conversion and Management, Vol. 64, pp. 273-288.

[6] Ding, F., Li, P., Huang, B., Gao, F., Ding, C. and Wang, C. (2010), Modeling and simulation of grid-connected hybrid photovoltaic/battery distributed generation system, China Int. Conference on Electricity Distribution (CICED) 2010 Proceedings, p. 1-10.

[7] Choudar, A., Boukhetala, D., Barkat, S. and Brucker, J.M. (2015), A local energy management of a hybrid PV-storage based distributed generation for microgrids, Energy Conversion and Management, Vol. 90, pp. 21-33.

[8] Márquez, J.L., Molina, M.G. and Pacas, J.M. (2010), Dynamic modeling, simulation and control design of an advanced micro-hydro power plant for distributed generation application, International Journal of Hydrogen Energy, Vol. 35, No. 11, pp. 5772-5777.

[9] Xavier, G.A., Filho, D.O. and Martins, J.H. (2015), Simulation of Distributed Generation with Photovoltaic Microgrids - Case Study in Brazil, Energies, Vol. 8, No. 5, pp. 4003-4023.

[10] Sharma, H. and Kaur, G. (2016), Optimization and simulation of smart grid distributed generation: A case study of university campus, 2016 IEEE Smart Energy Grid Engineering (SEGE), pp. 153-157.

[11] http://www.citect.schneider-electric.com. 